\title{
ANALYSIS OF JET FLAMES AND UNIGNITED JETS FROM UNINTENDED RELEASES OF HYDROGEN*
}

\author{
Houf, W.G. ${ }^{1}$, Evans, G.H. ${ }^{2}$ and Schefer, R.W. ${ }^{3}$ \\ ${ }^{1}$ Sandia National Laboratories, Livermore, CA 94551-0969, USA, will@sandia.gov \\ ${ }^{2}$ Sandia National Laboratories, Livermore, CA 94551-0969, USA, evans@sandia.gov \\ ${ }^{3}$ Sandia National Laboratories, Livermore, CA 94551-0969, USA, rwsche@sandia.gov
}

\begin{abstract}
A combined experimental and modeling program is being carried out at Sandia National Laboratories to characterize and predict the behavior of unintended hydrogen releases. In the case where the hydrogen leak remains unignited, knowledge of the concentration field and flammability envelope is an issue of importance in determining consequence distances for the safe use of hydrogen. In the case where a high-pressure leak of hydrogen is ignited, a classic turbulent jet flame forms. Knowledge of the flame length and thermal radiation heat flux distribution is important to safety. Depending on the effective diameter of the leak and the tank source pressure, free jet flames can be extensive in length and pose significant radiation and impingement hazard, resulting in consequence distances that are unacceptably large. One possible mitigation strategy to potentially reduce the exposure to jet flames is to incorporate barriers around hydrogen storage equipment. The reasoning is that walls will reduce the extent of unacceptable consequences due to jet releases resulting from accidents involving highpressure equipment. While reducing the jet extent, the walls may introduce other hazards if not configured properly. The goal of this work is to provide guidance on configuration and placement of these walls to minimize overall hazards using a quantitative risk assessment approach. Detailed Navier-Stokes calculations of jet flames and unignited jets are used to understand how hydrogen leaks and jet-flames interact with barriers. The effort is complemented by an experimental program that considers the interaction of jet flames and unignited jets with barriers.
\end{abstract}

\subsection{INTRODUCTON}

The development and commercial use of hydrogen will require safety guidelines for building vehicle fueling stations, storage facilities, and other infrastructure components. Validated engineering models of unintended hydrogen releases are needed for scenario and risk analysis. The purpose of current research being carried out at Sandia National Laboratories is to develop a scientific basis for evaluating credible safety scenarios and to provide technical data for hydrogen codes and standards decisions. An important issue in leak scenario analysis is the determination of the concentration decay of an unignited hydrogen jet in surrounding air, and the envelope of locations where the concentration falls below the point where ignition can occur (the lower flammability limit). In the case where a high-pressure leak of hydrogen is ignited, a classic turbulent jet flame forms and knowledge of the flame length and thermal radiation heat flux distribution is important to safety.

Previous work performed by Sandia on unintended releases of hydrogen [1-3] focused on these highmomentum large-scale ignited and unignited free hydrogen jet flames and jets. For ignited free jets, correlations based on experimental measurements were developed to characterize the visible flame length and radiative heat flux as a function of leak geometry and source pressure. For unignited leaks, classic jet scaling laws with under-expanded jet flow models were used to predict the concentration decay to the lower flammability limit. These models were validated against large-scale field experiments for hydrogen jet flames and lab-scale experiments for unignited jet concentration decay $[3]$.

\footnotetext{
* Sandia National Laboratory, Livermore, CA

Sandia is a multiprogram laboratory operated by Sandia Corporation, a Lockheed Martin Company, for the United States Department of Energy's National Nuclear Security Administration under Contract DE-AC04-94-AL85000. 
Depending on the effective diameter of the leak and the tank source pressure, results of these field tests and model calculations indicate that hydrogen jet flames can be extensive in length and pose significant radiation and impingement hazards, resulting in consequence distances that are unacceptably large. One possible mitigation strategy to potentially reduce the exposure to jet flames is to incorporate barriers around hydrogen storage equipment. The reasoning is that walls will reduce the extent of unacceptable consequences due to jet releases resulting from accidents involving highpressure equipment. While reducing the jet extent, the walls may introduce other hazards if not configured properly. Hence, the goal of the current Sandia work is to provide guidance on configuration and placement of these walls to minimize overall hazards using a quantitative risk assessment approach [23].

The flowfield produced from the interaction of an unintended release with a barrier is complex and the engineering models previously developed for free jet flames and unignited jets are not suited for the analysis of barrier impingement flow. In this case we are using detailed Navier-Stokes calculations of jet flames and unignited jets to understand how hydrogen leaks and jet flames interact with barriers. This effort is again complemented by an experimental program that considers the interaction of jet flames and unignited jets with barriers.

To initiate the modeling of interaction of unintended releases with barriers we have chosen to first validate the ability of our Reynolds-Averaged Navier-Stokes (RANS) model to predict the free hydrogen jet flames and free unignited jets that we previously modeled with validated engineering models. Once the validity and range of uncertainty of the Reynolds-Averaged Navier-Stokes model is established by comparison to these experiments and validated simulations it will be applied to perform barrier interaction calculations. As data becomes available from planned Sandia hydrogen jet flame barrier impingement field tests and lab-scale barrier unignited jet interaction experiments it will be used to validate the Reynolds-Averaged Navier-Stokes barrier impingement simulations.

\subsection{VALIDATION OF NUMERICAL SOLUTIONS FOR FREE JETS}

\subsection{Numerical Model}

Although the main objective of this work is to predict the effect of barriers on hydrogen jet flames, to obtain confidence and quantify the uncertainty in the modeling results, several turbulent free jets, both unignited and ignited, were simulated and compared with experimental data and correlations obtained from the literature to validate the model. These results are presented in the next sections in order of increasing complexity.

Three-dimensional simulations of the ignited and unignited turbulent free jets were performed with the Sandia developed FUEGO code. The FUEGO code was designed to simulate turbulent, reacting flow and heat transfer [4] on massively parallel computers, with a primary focus on heat transfer to objects in pool fires. More recently the code has been adapted for compressible flow and hydrogen combustion. The discretization scheme in FUEGO is based on the control volume finite element method (CVFEM; [5]), where the partial differential equations for conservation of mass, momentum, and energy are integrated over control volumes. A two equation $(k-\varepsilon)$ turbulence model is applied to close the Favre averaged equations. Transport equations are solved for the mass fractions of each chemical species except for the dominant species $\left(\mathrm{N}_{2}\right.$ in the present simulations) which is computed by constraining the sum of the species mass fractions to equal one. For compressible flow, the ideal gas equation of state is used to relate the density and pressure of the gas mixture. Radiation heat transfer is calculated with the Sandia developed finite element code SYRINX [6], a discrete ordinates, participating media radiation heat transfer code that is coupled to FUEGO. Combustion is modeled with the EDC model of Magnussen [7], in which the time scale for chemical reaction is based on the integral turbulent time scale as given by $k / \varepsilon$. Results have been obtained for the standard $k-\varepsilon$ model [8] and the RNG $k-\varepsilon$ model [9]. The convection terms in the equations are discretized with a first order upwind differencing scheme although the higher order MUSCL [10] scheme has also been used for some solutions. 


\subsection{Unignited Incompressible Turbulent Air Jet}

The simplest turbulent jet studied was an isothermal round jet of air into air at a Reynolds number $\left(\operatorname{Re}_{d}=w_{j} d / v\right)$ of 13,200. This jet was studied experimentally by Abdel et al. [11]. The jet emerges from a $2 \mathrm{~cm}$ diameter hole in a flat plate with a velocity of $1000 \mathrm{~cm} / \mathrm{s}$, a flat velocity profile, and a turbulence intensity of $10 \%$ (inlet values of $k$ and $\varepsilon$ are $1.5 \times 10^{4} \mathrm{~cm}^{2} / \mathrm{s}^{2}$ and $2.156 \times 10^{6} \mathrm{~cm}^{2} / \mathrm{s}^{3}$, respectively). The properties of air were evaluated at $1.0133 \mathrm{bar}(1 \mathrm{~atm})$ and $298 \mathrm{~K}$. The jet was computed on a three-dimensional computational domain consisting of a $100 \mathrm{~cm}$ tall by $60 \mathrm{~cm}$ diameter cylinder with the jet on axis and entering the domain at one end of the cylinder. A constant pressure boundary condition was applied around the circumference and at the open end of the cylinder. Results were computed on two hexagonal element meshes $\left(5.9 \times 10^{4}\right.$ and $4.8 \times 10^{5}$ elements where the refined mesh is obtained by dividing each coarse mesh element into 8 smaller elements) that expanded in both the axial and radial directions from the jet. Results were obtained for the standard $k-\varepsilon$ and RNG $k-\varepsilon$ turbulence models and for two convection operators, the 1st order upwind scheme and MUSCL scheme [4]. The figure of merit for the accuracy of the simulation is based on the centerline velocity decay, which in the self-similar region of a free turbulent jet is correlated by an expression of the form

$$
w_{j} / w_{\mathrm{cl}}=\left(1 / C_{1}\right) z / d+C_{2}
$$

where $w_{j}$ is the jet inlet velocity, $w_{\mathrm{cl}}$ is the jet centerline velocity at axial distance $z$ from the jet inlet, $d$ is the jet inlet diameter. The constant $C_{2}$ is related to the so-called virtual origin of the jet, and depends on jet conditions and the non-similar region of the jet. The constant $C_{1}$ is the velocity decay constant and is reported in the literature to vary between 5 and 6.5 [11-13]. Results of the air-air jet simulation with FUEGO are shown in Fig. 2.1. The mesh sensitivity of $C_{1}$ is approximately $10 \%$ when the number of elements is changed by a factor of 8 . The results show increased jet spreading (larger slopes in Fig. 2.1; smaller values of $C_{1}$ ) with (1) increased mesh resolution, (2) the use of the RNG $k-\varepsilon$ turbulence model compared to the standard $k-\varepsilon$ turbulence model, and (3) the use of the MUSCL convection operator compared to the $1^{\text {st }}$ order upwind convection operator. All jet simulation results are within the uncertainty of experimental results for the velocity decay constant (5 to 6.5) reported in the literature, with the exception of the case of the RNG $k-\varepsilon$ turbulence model combined with the MUSCL convection operator which predicted a significantly larger jet spreading rate.

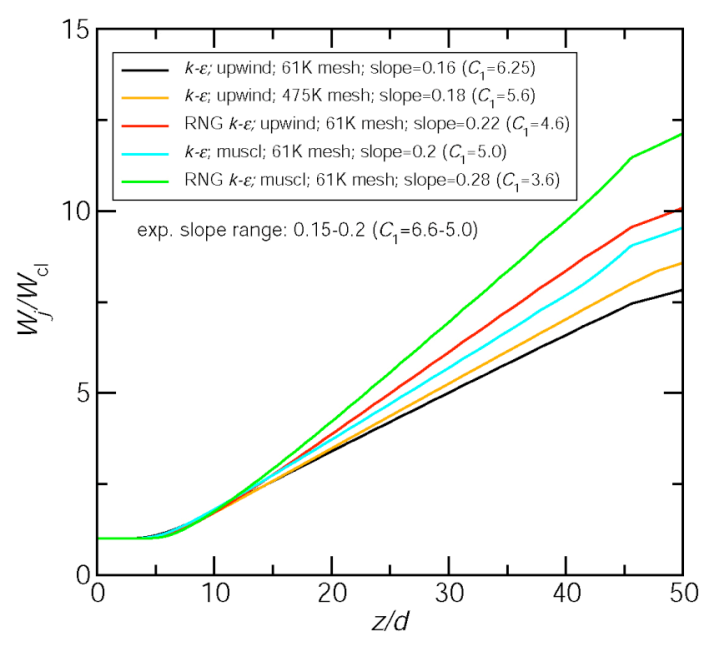

Figure 2.1 Centerline velocity decay of turbulent, isothermal, incompressible jet $\left(\operatorname{Re}_{d}=13,200\right)$; effects of mesh, turbulence model, and convection operator.

\subsection{Unignited Incompressible Turbulent $\mathrm{H}_{2}$-Air Jet}

Simulations were next performed for an unignited incompressible hydrogen jet into air. An incompressible jet of hydrogen at a Reynolds number $\left(\mathrm{Re}_{d}\right)$ of 13,200 was simulated for jet inlet diameters of $2 \mathrm{~cm}$ (not shown) and $6.2 \mathrm{~cm}$ (the larger diameter jet will be the subject of studies discussed later). For the hydrogen into air jet, the figures of merit that determine the accuracy of the 
simulation are the decay constants for velocity and hydrogen concentration along the jet centerline. When the density of the jet fluid differs from that of the ambient fluid the centerline velocity decay law is modified by replacing the jet diameter, $d$, with the momentum diameter, $d^{*}=d\left(\rho_{j} / \rho_{\mathrm{amb}}\right)^{1 / 2}$. The velocity decay expression is of the form [14]

$$
w_{j} / w_{\mathrm{cl}}=\left(1 / C_{1}\right) z / d^{*}+C_{2} \text { where } d^{*}=d\left(\rho_{j} / \rho_{\mathrm{amb}}\right)^{1 / 2}
$$

where the value of $C_{1}$ is approximately 5 , which is within the range (5-6.5) of decay constants reported in the literature for constant density jets as noted above. Similarly, the decay law for the centerline mass fraction $Y_{\mathrm{cl}}$ of the jet species (e.g., jet of $\mathrm{H}_{2}$ into air) is given by an expression of the form [15]

$$
1 / Y_{\mathrm{cl}}=\left(1 / C_{3}\right) z / d^{*}+C_{4}
$$

where the value of $C_{3}$ is approximately 4.8. The analogous expression for decay of the centerline mole fraction, $X_{\mathrm{cl}}$, of the jet species is of the form

$$
1 / X_{\mathrm{cl}}=\left(1 / C_{5}\right) z / d^{\prime}+C_{6} \quad \text { where } d^{\prime}=d\left(\rho_{\mathrm{amb}} / \rho_{j}\right)^{1 / 2}
$$

where the value of $C_{5}$ is also approximately $5[16]$.

For the incompressible hydrogen jet, simulations of the velocity and mole fraction decay along the jet centerline are shown in Figs. 2.2(a) and (b), respectively. Results are reported for the standard and RNG $k-\varepsilon$ turbulence models, for inlet turbulence intensities ranging from $1 \%$ to $20 \%$, and for the $1^{\text {st }}$ order upwind and MUSCL convection operators, on two meshes. The results show relatively small effects of mesh spacing and inlet turbulence intensity on the decay constants $(13 \%$ reduction in the velocity decay constant for an 8 -fold increase in the number of elements and $7 \%$ reduction in the velocity decay constant for an increase in inlet turbulence intensity from $1 \%$ to $20 \%$ ). The centerline velocity and concentration decay constants are predicted to be approximately $30 \%$ to $40 \%$ larger (jet spreading rates smaller) than experimental values when the standard $k-\varepsilon$ model is used together with the $1^{\text {st }}$ order upwind convection operator. Significantly better agreement is obtained when either the RNG $k-\varepsilon$ turbulence model or the MUSCL convection operator is applied.
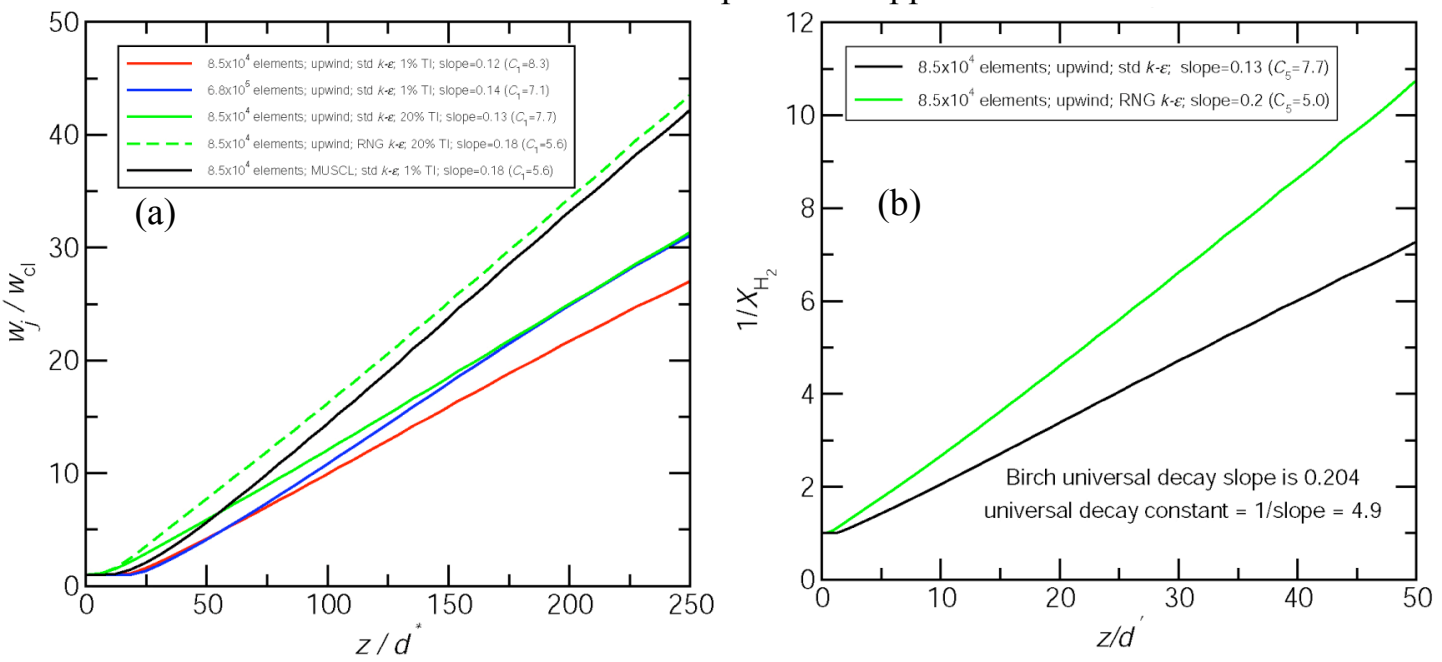

Figure 2.2. (a) Centerline velocity decay of turbulent, isothermal, incompressible $\mathrm{H}_{2}$-air jet $\left(\operatorname{Re}_{d}=13,200\right)$; effects of mesh, turbulence model, turbulence intensity, and convection operator; $d^{*}=d\left(\rho_{j} / \rho_{\mathrm{amb}}\right)^{1 / 2}$; (b) Centerline $\mathrm{H}_{2}$ mole fraction decay of isothermal, incompressible $\mathrm{H}_{2}$-air jet $\left(\operatorname{Re}_{d}=13,200\right)$; effect of turbulence model; $d^{\prime}=d\left(\rho_{\text {amb }} / \rho_{j}\right)^{1 / 2}$. 


\subsection{Unignited Compressible Turbulent $\mathrm{H}_{2}$-Air Jet}

Birch et al. $[12,17]$ studied underexpanded jets of natural gas, ethylene, and air at pressures up to $70 \mathrm{bar}$ and found that the centerline velocity and mole fraction scaling laws for incompressible jets could be applied to compressible, underexpanded jets if the jet diameter is replaced with a larger diameter. The larger diameter is determined from an analysis that includes an isentropic expansion of an ideal gas from stagnation conditions within the supply tank to the sonic condition at the jet opening followed by application of conservation of mass and momentum outside the jet opening. An idealized condition is assumed downstream of the jet opening where the jet has expanded to a larger diameter and the pressure and temperature of the jet have equilibrated with the ambient conditions. For the momentum balance, the assumption was made that the jet expanded immediately outside the opening to the pseudo-diameter, which was then computed. The analysis in [12] gave a centerline velocity decay constant of 4.8 and a centerline mole fraction decay constant of 5.4. A description of the pseudo-diameter approach applied to underexpanded hydrogen jet flames has been given recently in [1], where due to the high tank pressures 413.6bar $(6,000 \mathrm{psi})$, the non-ideal gas behavior of hydrogen was taken into account by using an Abel-Noble equation of state in the isentropic expansion from tank conditions to the jet opening. From a CFD perspective the concept of using a pseudo-diameter for the jet opening is attractive if the velocity at the pseudo-diameter is subsonic. In this case, the boundary condition for a turbulent jet calculation avoids the necessity of making a difficult calculation of the supersonic expansion between the sonic condition at the jet opening and the eventual subsonic flow downstream in the ambient. However, the analysis given by Birch et al. [12] does not avoid a supersonic condition at the pseudo-diameter. An alternative approach that does yield a subsonic condition is the Mach disk analysis [18]. In the Mach disk analysis an isentropic expansion is assumed between stagnation conditions upstream of the jet opening and the sonic condition at the jet exit. An isentropic expansion is also assumed from the jet exit to just upstream of the Mach disk where normal shock relations as given in Shapiro [19] are applied to give conditions downstream of the Mach disk. In the present analysis all the gas flowing through the jet opening is assumed to pass through the Mach disk. The computed Mach disk diameter becomes the pseudo-diameter for the jet simulation and the post shock velocity and temperature become the jet exit conditions. Hence, the Mach disk model provides a subsonic jet inflow boundary condition for the FUEGO simulations discussed below.

The recent high pressure, underexpanded hydrogen jet flame experiment of Schefer et al. [1] provides important data for model validation. The visible flame length and the spatial distribution of radiation heat flux are two metrics for validation. From a computational point of view the problem is complex, including compressible flow, turbulence, combustion, and radiation. The experiment consisted of a blowdown from a tank connected to a stagnation chamber just upstream of the $5.08 \mathrm{~mm}$ diameter jet opening. During the blowdown which lasted about 10 minutes, the stagnation pressure and jet flame length gradually decreased. For code validation, a time of $100 \mathrm{sec}$ into the blowdown was selected when the stagnation pressure and temperature upstream of the jet opening were 104.8bar (1520psia) and $231.4 \mathrm{~K}$, respectively. At this pressure the compressibility factor is only a few percent and the computed Mach disk diameter and Mach number downstream of the Mach disk for these conditions, assuming the ideal gas equation of state, are $6.2 \mathrm{~cm}$ and 0.4 , respectively. This diameter is more than an order of magnitude larger than the actual diameter $(5.08 \mathrm{~mm})$. The effects of this approximation on the predictions of velocity and concentration decay of a combusting jet and on flame length are unknown.

Calculations were first carried out for unignited $\mathrm{H}_{2}$ jets at the above Mach disk conditions to compare computed centerline velocity and concentration decay constants with values found in the literature for underexpanded jets. The 3D FUEGO calculations were performed for a $2,500 \mathrm{~cm}$ long by $1,250 \mathrm{~cm}$ diameter cylinder with the jet on axis and entering the domain at one end of the cylinder. A constant pressure boundary condition was applied around the circumference of the cylinder and at the open end of the cylinder. Based on the Mach disk analysis discussed above the hydrogen was allowed to enter the domain through the $6.2 \mathrm{~cm}$ diameter opening with a Mach number of 0.4 (velocity of $4.482 \times 10^{4}$ $\mathrm{cm} / \mathrm{s}$ ) at a temperature of $219.8 \mathrm{~K}$. Predicted results for the centerline velocity decay are shown in Fig. 2.4a for two meshes and for both the standard and the RNG $k-\varepsilon$ turbulence models. There is about a 
$15 \%$ decrease in the velocity decay constant when the mesh is increased by a factor of 8 . The centerline velocity decay constant predicted by the standard $k-\varepsilon$ turbulence model $\left(\mathrm{C}_{1}=7.6\right)$ is larger than values in the literature obtained from experimental results whereas the RNG $k-\varepsilon$ turbulence model yields results $\left(\mathrm{C}_{1}=5.4\right)$ that are within the range (5-6.5) of experimental data. Fig. 2.4b shows a comparison between the predicted results for centerline decay of velocity and $\mathrm{H}_{2}$ mass fraction obtained with the two turbulence models on the $400 \mathrm{~K}$ element mesh. The centerline mass fraction decay constant is about 5\% smaller than the velocity decay constant for both models. This result appears to be consistent with results in the literature although uncertainties in decay constants are typically $10 \%$. We note that the turbulent Prandtl and Schmidt numbers used in the calculations were 0.9 .
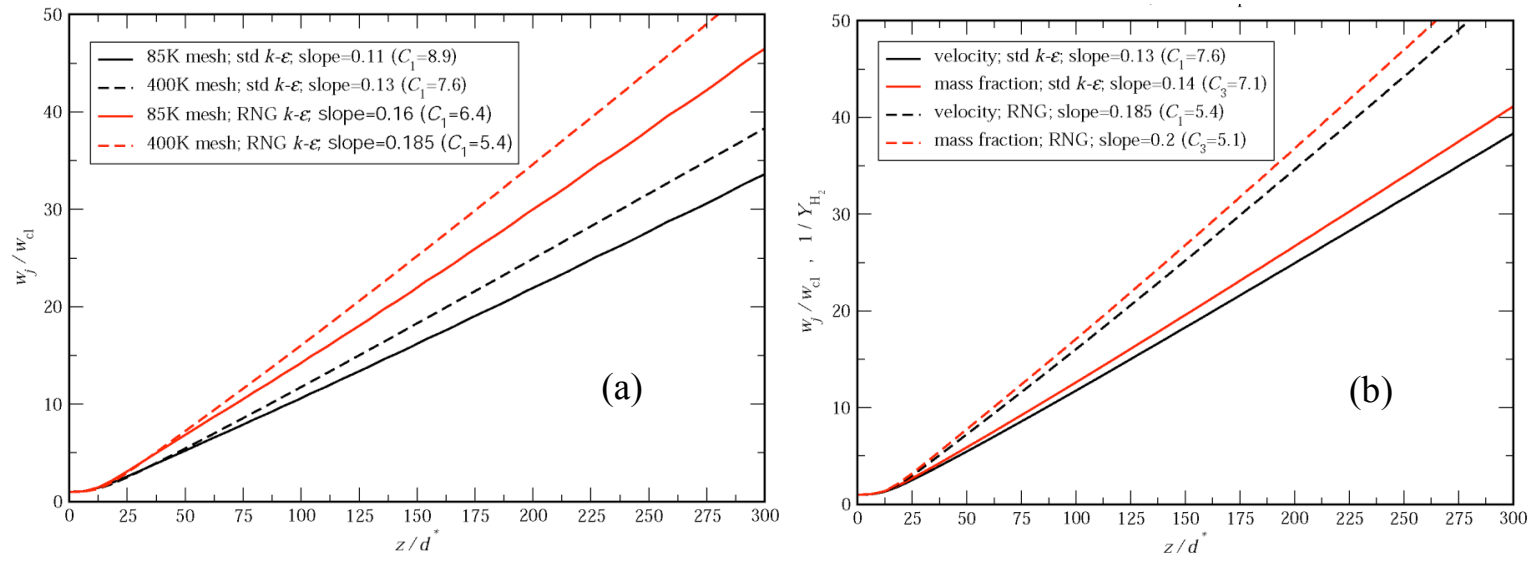

Figure 2.4. (a) Effects of mesh and turbulence model on centerline decay of velocity for an unignited, turbulent, compressible $\mathrm{H}_{2}$-air jet $\left(\mathrm{M}=0.4 ; \mathrm{Re}_{d}=4.2 \times 10^{5}\right)$; (b) comparison of centerline decay of velocity and $\mathrm{H}_{2}$ mass fraction for the finer mesh $\left(4 \times 10^{5}\right.$ elements).

\subsection{Incompressible Turbulent $\mathrm{H}_{2}$-Air Jet Flame}

The atmospheric pressure, undiluted hydrogen jet flame A experiment of Barlow and Carter [20] was simulated with FUEGO to test the hydrogen combustion model. This experiment has been studied and simulated by other researchers and has been the subject of several workshops on turbulent diffusion flames [21]. Because the exiting hydrogen jet is at atmospheric pressure the flow is not complicated by the underexpanded jet shock structure that exists for high pressure releases such as the hydrogen jet flame experiments of Schefer et al. [1]. In this experiment the $\mathrm{H}_{2}$ jet emerges from a straight $3.75 \mathrm{~mm}$ diameter tube (outside diameter of $4.84 \mathrm{~mm}$ ) at $\operatorname{Re}_{\mathrm{d}}=10,000$ with a fully developed turbulent velocity profile. In the experiment there was a co-flow of air with a velocity of $1.0 \mathrm{~m} / \mathrm{s}$ surrounding the $\mathrm{H}_{2}$ jet. The air temperature was $294 \mathrm{~K}$ and the turbulence intensity of the air was not measured but presumed to be quite low (less than $2 \%$ ). The turbulence intensity of the jet was not measured.

The computational domain for the jet flame simulation is shown in Fig. 2.5. The hydrogen jet was

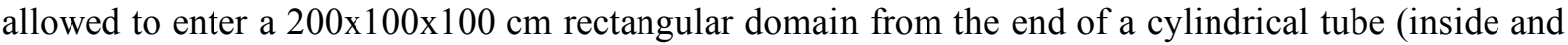
outside diameters of $3.75 \mathrm{~mm}$ and $4.84 \mathrm{~mm}$, respectively) that extends $50 \mathrm{~cm}$ from one end of the domain. The computational domain was discretized into $6 \times 10^{5}$ elements with nonuniform size (finer mesh at end of tube, $z=0$ ). The boundary condition for the jet exit was a uniform velocity of $2.96 \times 10^{4}$ $\mathrm{cm} / \mathrm{s}$ at the end of the tube. The outer boundaries of the rectangular domain were defined as open boundaries with a constant pressure boundary condition. For the surface upstream of the jet exit $(z=-$ $50 \mathrm{~cm}$ in Fig. 2.5) where the co-flow of air enters the domain, the velocity, turbulence intensity, turbulence length scale, and temperature were specified to be $100 \mathrm{~cm} / \mathrm{s}, 0.1 \%, 4.84 \mathrm{~mm}$, and $294 \mathrm{~K}$, respectively.

The EDC combustion model for hydrogen in FUEGO is a one-step, irreversible conversion of $\mathrm{H}_{2}$ and $\mathrm{O}_{2}$ to $\mathrm{H}_{2} \mathrm{O}$. The rate of conversion is governed by the turbulence time scale, $k / \varepsilon$. Radiative heat loss from hydrogen flames is important in determining the flame temperature [20]. The radiative heat loss from the flame was computed using the Sandia developed SYRINX participating media discrete 
ordinates radiative transfer code that is coupled to FUEGO. Four ordinates ( 24 directions) were used in SYRINX for the radiation simulation and the spatially-dependent absorption coefficients were determined by using the $\mathrm{H}_{2} \mathrm{O}$ mass fractions computed by FUEGO with the absorption model of Leckner [22]. A comparison of the calculated and measured centerline temperature distributions are shown in Fig. 2.6. Predicted temperature profiles are shown for jet inlet turbulence intensities of $2 \%$ and $10 \%$ with both the standard and RNG $k-\varepsilon$ turbulence models. The calculated results are for the $1^{\text {st }}$ order upwind convection operator. The agreement between the predicted and measured temperature profiles is reasonably good; the peak predicted temperature is within $6 \%$ of the data and the location of the peak temperature (normalized by the visible flame length of $67.5 \mathrm{~cm}$ ) is predicted to be within $15 \%$ of the data. The effect of inlet turbulence intensity on the predicted temperature profile is small and the temperature data falls between the predictions of the two turbulence models.

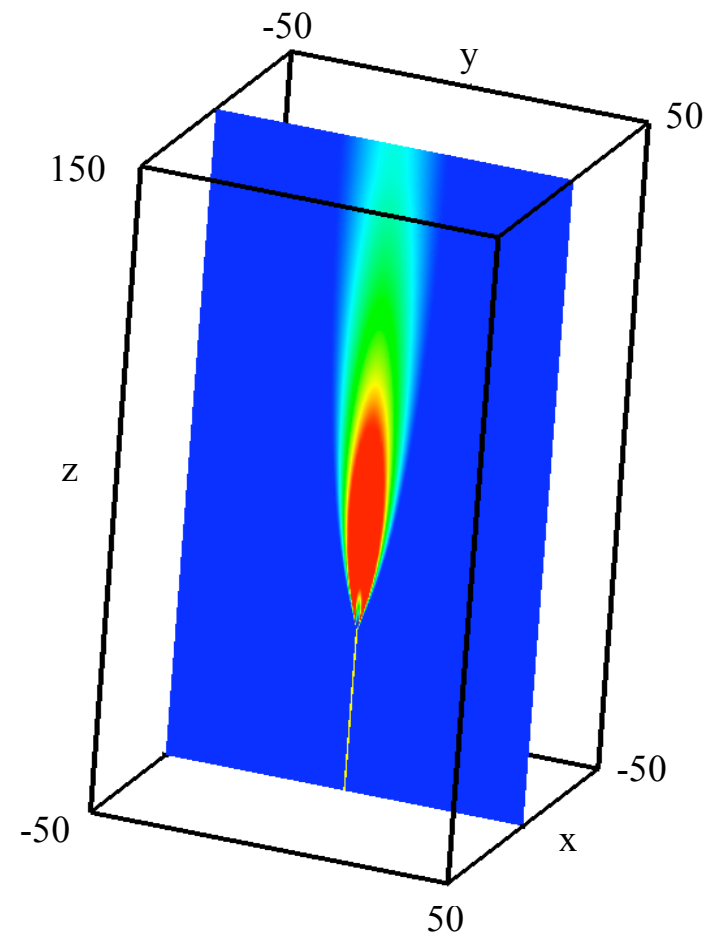

Figure 2.5. Computational domain and cut plane showing computed temperature field for incompressible, turbulent $\mathrm{H}_{2}$-air jet flame (flame $\mathrm{A}[20]$ ); $\mathrm{Re}_{d}=1.0 \times 10^{4}$.

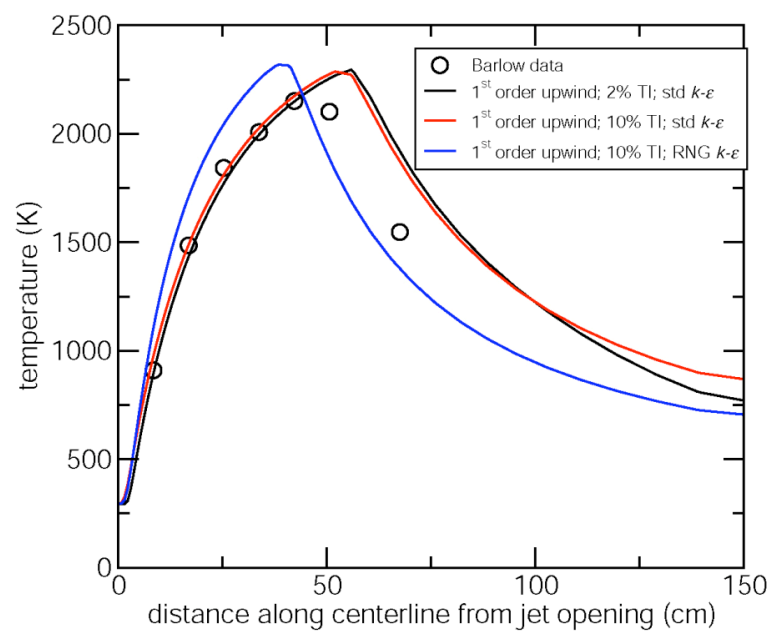

Figure 2.6. Jet centerline temperature distributions for incompressible, turbulent $\mathrm{H}_{2}$-air jet flame (flame A [20]); $\operatorname{Re}_{d}=1.0 \times 10^{4}$. 


\subsection{Compressible Turbulent $\mathrm{H}_{2}$-Air Jet Flame}

The next level of complexity in the verification sequence is the large-scale compressible turbulent hydrogen jet flame experiment of Schefer et al. [1]. The experiment resulted in an unimpeded hydrogen jet flame with a visible flame length of approximately $10 \mathrm{~m}$. The experiment was designed to produce a choked flow at the jet opening $(5.08 \mathrm{~mm}$ diameter tube) and hence the flowfield directly downstream of the jet exit contains an underexpanded jet region with shocks. The presence of this underexpanded jet region adds an extra layer of complexity to the simulation not present in the simulation of the Barlow and Carter [20] hydrogen flame where the jet exit velocity was subsonic and contained no downstream shocks. To simulate the Schefer et al. experiment with the FUEGO code the underexpanded jet region was modeled using the single Mach disk approach discussed in Section 2.4. The computed Mach disk diameter becomes the pseudo-diameter for the jet simulation and the post shock velocity and temperature become the jet exit conditions.

Figure 2.7 shows results of the FUEGO jet flame simulations, where computed centerline temperature distributions are compared with those from several experiments (filled symbols are from the compressible jet flames of [2]). In Fig. 2.7 the distance from the jet exit has been normalized with the visible flame length from the experiment [1], which was $6.7 \mathrm{~m}$ at $100 \mathrm{~s}$. A calculation without radiation (not shown) resulted in a significantly higher temperature and a longer visible flame length compared with experimental data. The predicted centerline temperature was found to be sensitive to the level of inlet turbulence intensity between $5 \%$ and $20 \%$, but not sensitive to inlet turbulence intensities at levels greater than $20 \%$. The radiation absorption coefficient was also varied $\pm 30 \%$ from the nominal value, but resulted in a predicted variation in the centerline temperature distribution of only a few percent (also not shown). Comparisons of results using the standard $k$ - $\varepsilon$ turbulence model and the RNG $k-\varepsilon$ turbulence models showed significant differences, with the RNG model producing significantly better agreement with experimental data. In general the predicted results showed a slower temperature rise and a longer visible flame length than the experimental data. However, the RNG results were within the experimental uncertainty for peak centerline temperature and visible flame length.

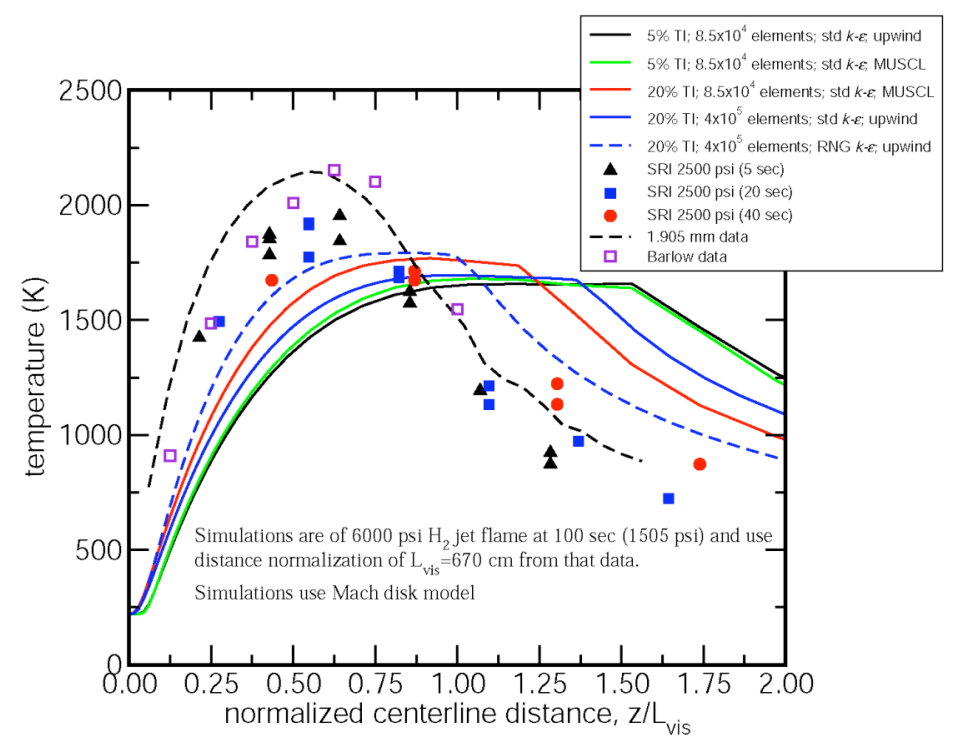

Figure 2.7. Jet centerline temperature distributions for compressible, turbulent $\mathrm{H}_{2}$-air jet flame (flame of [1] at 100s; calculations use Mach disk model for jet boundary condition: $u=4.482 \times 10^{4} \mathrm{~cm} / \mathrm{s} ; d=6.2$ $\mathrm{cm} ; \operatorname{Re}_{d}=4.2 \times 10^{5}$ ).

\subsection{Summary of unignited and ignited free jet validation study}

The velocity decay constants for the unignited free jets obtained using the FUEGO simulations discussed above are summarized in Table 2.1 for the standard $k-\varepsilon$ and the RNG $k-\varepsilon$ turbulence models. These results are for incompressible air into air and $\mathrm{H}_{2}$ into air and compressible $\mathrm{H}_{2}$ into air using the 
$1^{\text {st }}$ order upwind convection operator. The results for all the free jets studied are consistent in that the velocity decay constant obtained with the standard $k-\varepsilon$ model is larger than that obtained with the RNG $k-\varepsilon$ model. Although the results for the air into air jet show that the standard $k-\varepsilon$ model gives reasonable agreement with experimental data and the RNG $k-\varepsilon$ model yields a velocity decay constant that is somewhat below the experimental data range, the results for incompressible and compressible $\mathrm{H}_{2}$ into air jets show that the RNG results fall within the range of the data and the standard $k-\varepsilon$ model results predict a velocity decay constant that is significantly larger than the data. Thus, for the barrier studies discussed below we have used the RNG $k-\varepsilon$ turbulence model. The RNG $k-\varepsilon$ turbulence model results for the concentration decay of $\mathrm{H}_{2}$ (either mass or mole fraction) show decay constants ranging from 5.0 to 5.5 which are in good agreement with experimental data. The MUSCL convection operator with standard $k-\varepsilon$ model yielded velocity decay constants in the range of 5-5.5 for all cases listed in Table 2.1. Using the MUSCL scheme with the RNG $k-\varepsilon$ turbulence model resulted in a decrease in the velocity decay constants of approximately $28 \%$, causing them to fall below the range of acceptable values reported in the literature.

Table 2.1. Predicted velocity decay constants for turbulent free jets using FUEGO and $1^{\text {st }}$ order upwind convection.

\begin{tabular}{|c|c|c|c|}
\hline & $\begin{array}{c}\mathrm{Re}_{d}=13,200 \\
\text { air into air }\end{array}$ & $\begin{array}{c}\mathrm{Re}_{d}=13,200 \\
\mathrm{H}_{2} \text { into air }\end{array}$ & $\begin{array}{c}\mathrm{Re}_{d}=4.2 \times 10 \\
5 \\
\mathrm{H}_{2} \text { into air }\end{array}$ \\
\hline std $k-\varepsilon$ & $5.6-6.3$ & $7.1-8.3$ & $7.6-8.9$ \\
\hline RNG $k-\varepsilon$ & 4.6 & 5.6 & $5.4-6.4$ \\
\hline
\end{tabular}

For the $\mathrm{H}_{2}$ free jet flame, predictions of centerline temperature distributions were compared with experimental data for both incompressible and compressible (using the Mach disk model) jets. Good agreement with the measured centerline temperature distribution was obtained for the incompressible flame A of Barlow and Carter [20]. For the underexpanded free jet flame of Schefer et al. [1] the results from the RNG $k-\varepsilon$ turbulence model using $20 \%$ inlet turbulence intensity agreed reasonably well with measured centerline temperature profiles, especially for the Sandia 172.4 bar (2500 psi) $\mathrm{H}_{2}$ jet flame at 40 seconds.

\subsection{HYDROGEN BARRIER IMPINGEMENT STUDIES}

Previous studies have shown that jet flames resulting from unintended releases of hydrogen can be extensive in length and pose significant radiation and impingement hazards, resulting in consequence distances that are unacceptably large [1-3]. One possible mitigation strategy to potentially reduce the exposure to jet flames is to incorporate barriers around hydrogen storage equipment. While reducing the jet extent, the walls may introduce other hazards if not properly configured. The goal of this work is to provide guidance on configuration and placement of these walls to minimize overall hazards.

To begin this work we are using detailed Reynolds-Averaged Navier-Stokes calculations of jet flames and unignited jets to understand how hydrogen leaks and jet-flames interact with barriers. The effort is complemented by an experimental program that considers the interaction of jet flames and unignited jets with barriers. Work in the area of barriers falls under three categories: the characterization of steady-state jet flame-wall interactions, the characterization of overpressures formed during transient startup of $\mathrm{H}_{2}$ releases near a barrier, and the incorporation of risk analysis to identify safe barrier wall design.

In the area of jet flame-wall interactions we have planned a series of jet-flame wall interaction tests that will be carried out in collaboration with SRI International at their Corral Hollow test site in Tracy, CA, where cinderblock walls will be constructed for long duration tests (a full 6 pack of $\mathrm{H}_{2}$ provides a test duration of about 5 minutes). The experiments will measure flame characteristics (flame length, radiative heat transfer, gas and wall temperatures) for various wall heights, hydrogen flow rates and separation distances between the wall and the flame origin. The experimental setup is shown 
schematically in Fig. 3.1. In the initial tests, flames will be orientated horizontally (leak direction labeled $b$ ) with the walls vertical to mimic the most likely release configuration.

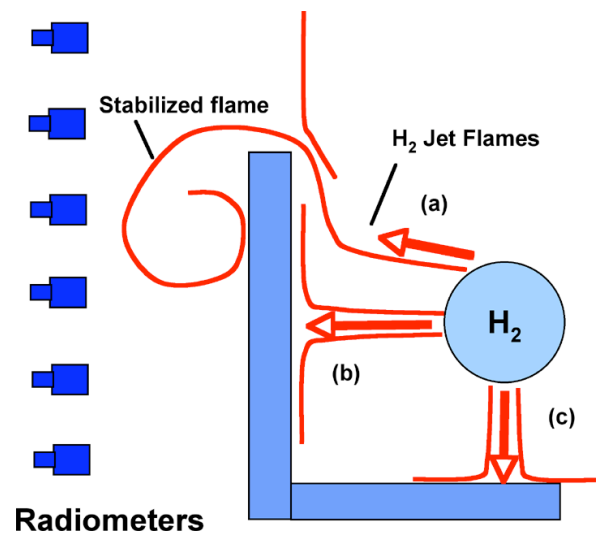

Figure 3.1. Steady-state flame/barrier wall interaction experiment. Radiometers will be located at various positions to measure radiative heat transfer from the flame.

This initial hydrogen jet flame impingement experimental test geometry (leak direction labeled b) was modeled with the FUEGO turbulent reacting flow code discussed in Section 2.0. The geometry consists of a $2.44 \mathrm{~m}$ by $2.44 \mathrm{~m}$ ( $8 \mathrm{ft}$ by $8 \mathrm{ft}$ ) barrier that is 0.2 meters thick. Hydrogen exits from a $5.018 \mathrm{~mm}$ round pipe pointed directly at the center of the barrier a distance of $1.22 \mathrm{~m}(4 \mathrm{ft})$ away from the barrier and $1.22 \mathrm{~m}(4 \mathrm{ft})$ above the ground. The three-dimensional computational domain consisted of a $767.3 \mathrm{~cm}$ by $747 \mathrm{~cm}$ by $625 \mathrm{~cm}$ rectangular domain with approximately $10^{6}$ computational cells, where the vertical symmetry plane through the jet and barrier wall centerline was used to reduce the number of cells ( $y-z$ axis in Fig. 3.2). Exit conditions for the jet were assumed to be the same as those used for the simulations of the free jet flame experiments of Schefer et al. [1] in Section 2.5 and the underexpanded jet region was again modeled using the single Mach disk approach discussed in Section 2.4. All boundaries except the jet inlet, the ground, and the symmetry plane were modeled as open boundaries with a constant pressure boundary condition. Based on the FUEGO model validation studies discussed in Section 2.0, the upwind convective difference scheme with RNG $k-\varepsilon$ turbulence model was chosen for the simulations because this combination yielded the best agreement with the hydrogen free jet-flame data and the unignited jet concentration decay scaling-laws. Figure 3.2 shows the temperature profile of the simulation of the hydrogen jet flame impinging on the barrier wall. Preliminary results indicate that the barrier wall is capable of deflecting a horizontal hydrogen jet flame that impinges on the wall at 90 degrees.

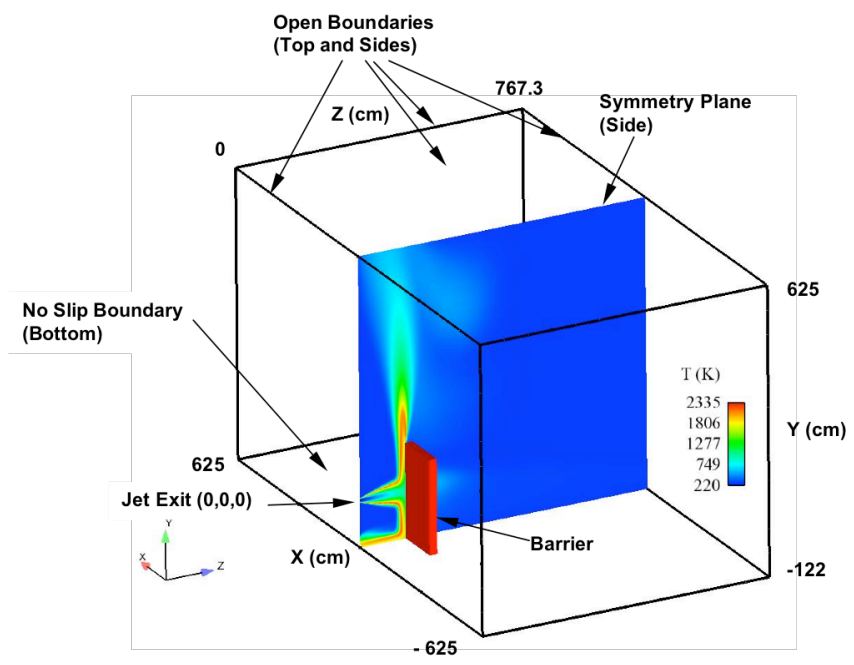

Figure 3.2 FUEGO simulation of impingement of a hydrogen jet-flame on a vertical barrier wall. 
Figure 3.3 shows a single frame from an infrared video recording taken from a previous hydrogen jet flame impingement experiment for a similar (perpendicular impingement) configuration. The infrared video was used to characterize the flame size and length. The horizontal jet flow issues from a $9 \mathrm{~mm}$ diameter tube and impinges onto a $2.4 \mathrm{~m}$ square vertical cinderblock wall. The distance between the leak and the wall is approximately $1.5 \mathrm{~m}$. The video image shows a 90 degree deflection of the flame similar to the model predictions in Figure 3.2. Future work will provide a more quantitative comparison between the experimental measurements and predicted shapes and lengths of the deflected flames.

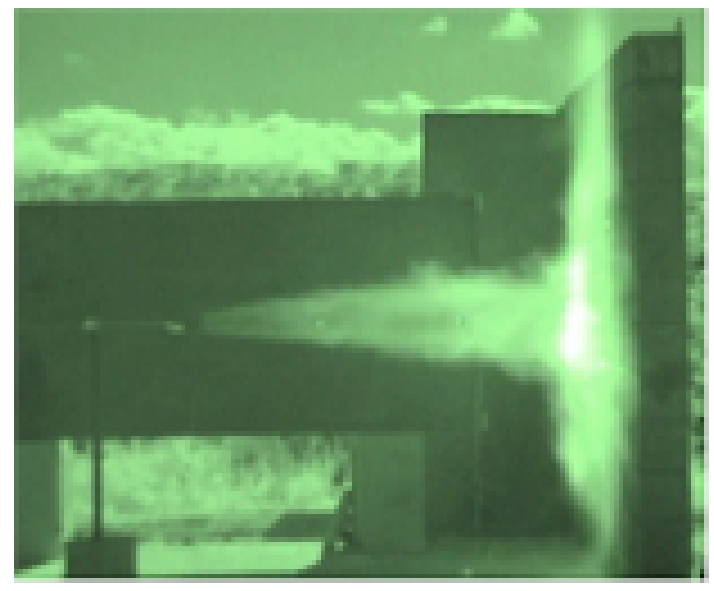

Figure 3.3 Infrared recording of previous barrier wall/flame interaction. Hydrogen leak diameter is $9 \mathrm{~mm}$ with the flow from left to right and normal to the vertical wall.

\subsection{SUMMARY}

A combined experimental and modeling study is being carried out to investigate the use of barriers to mitigate the effects of unintended releases of hydrogen. The goal of this work is to provide guidance on configuration and placement of these barriers to minimize overall hazards using a quantitative risk assessment approach. To begin the modeling studies we have validated the ability of our ReynoldsAveraged Navier-Stokes model to predict the free hydrogen jet flames and free unignited jets that we previously modeled with validated engineering models. The validity and range of uncertainty of the Reynolds-Averaged Navier-Stokes model has been established by comparison to these experiments and validated simulations. The $\mathrm{H}_{2}$ into air free jet simulations yielded velocity and concentration decay constants in good agreement (within 5\%) with experimental data when the RNG $k-\varepsilon$ turbulence model was used whereas in general the standard $k-\varepsilon$ model results were $20 \%$ to $30 \%$ larger. As a result of the free jet studies we have chosen the RNG $k$ - $\varepsilon$ turbulence model for the barrier simulations.

We are now applying the model to perform barrier interaction calculations and have successfully performed a three-dimensional simulation of a hydrogen jet flame impinging on a vertical barrier. We are using the detailed Reynolds-Averaged Navier-Stokes calculations to understand how hydrogen leaks and jet-flames interact with barriers and to help define the geometry and range of conditions for the experimental program. Results from the experimental field test program and lab-scale barrier unignited jet interaction experiments will provide further validation data for the Navier-Stokes barrier impingement simulations.

\subsection{ACKNOWLEDGMENTS}

This work was supported by the US Department of Energy, Office of Energy Efficiency and Renewable Energy, Hydrogen, Fuel Cells and Infrastructure Technologies Program under the Codes and Standards subprogram element managed by Patrick Davis and Antonio Ruiz.

\subsection{REFERENCES}

1. Schefer, R.W., Houf, W.G., Williams, T.C. Bourne, B., and Colton, J., "Characterization of High- 
Pressure, Under-Expanded Hydrogen-Jet Flames," Int. Jour. of Hydrogen Energy, In Press, Oct., 2006a.

2. Schefer, R.W., W.G. Houf, W.G., Bourne, B. and Colton, J., "Spatial and Radiative Properties of an Open-Flame Hydrogen Plume," Int. Jour. of Hydrogen Energy, Vol. 31, 1332-1340, Aug. $2006 \mathrm{~b}$.

3. Houf, W.G., and Schefer, R.W., "Predicting Radiative Heat Fluxes and Flammability Envelopes from Unintended Releases of Hydrogen," Int. Jour. of Hydrogen Energy, Vol. 32, pp. 136-151, Jan., 2007.

4. Moen, C. D., Evans, G. H., Domino, S. P. and Burns, S. P., A Multi-Mechanics Approach to Computational Heat Transfer, proceedings 2002 ASME Int. Mech. Eng. Congress and Exhibition, New Orleans, IMECE2002-33098, Nov. 17-22, 2002.

5. Schneider, G. E., Elliptic Systems: Finite-Element Method 1, Handbook of Numerical Heat Transfer (Minkowycz, W. J., Sparrow, E. M., Schneider, G. E. and Pletcher, R. H. Eds.), J. Wiley \& Sons, Inc., New York, 1988, ch. 10, pp. 379-420.

6. Burns, S. P., SYRINX - User's Manual, unpublished Sandia National Laboratories Report, August 5, 1999.

7. Magnussen, B. F., Modelling of $\mathrm{NO}_{\mathrm{x}}$ and Soot Formation by the Eddy Dissipation Concept, Int. Flame Research Foundation $1^{\text {st }}$ Topical Orientation Meeting, Amsterdam, 1989.

8. Launder, B. E. and Spalding, D. B., The Numerical Computation of Turbulent Flows, Comput. Meth. Appl. Mech. Eng., 3, 1974, pp. 269-289.

9. Papageorgakis, G. C. and Assanis, D. N., Comparison of Linear and Nonlinear RNG-based $k$ $\varepsilon$ Models for Incompressible Turbulent Flows, Num. Heat Transfer, Part B, 35, 1999, pp. 1-22.

10. Barth, T. J. and Jerpersen, D. C., The Design and Application of Upwind Schemes on Unstructured Meshes, $27^{\text {th }}$ Aerospace Sciences Meeting, Reno, AIAA-89-0366, 1989.

11. Abdel-Rahman, A. A., Chakroun, W. and Al-Fahed, S. F., LDA Measurements in the Turbulent Round Jet, Mechanics Research Comm., 24,No. 3, 1997, pp. 277-288.

12. Birch, A. D., Hughes, D. J. and Swaffield, F., Velocity Decay of High Pressure Jets, Combust. Sci. and Tech., 52, 1987, pp. 161-171.

13. Turns, S. R., An Introduction to Combustion - Concepts and Applications, 2000, McGraw-Hill, p. 443.

14. Wilson, R. A. M. and Danckwerts, P. V., Studies in turbulent mixing - II. A hot-air jet, Chem. Eng. Sci., 19, 1964, pp. 885-895.

15. Richards, C. D. and Pitts, W. M., Global density effects on the self-preservation behaviour of turbulent free jets, J. Fluid Mech., 254, 1993, pp. 417-435.

16. Chen, C. J. and Rodi, W., Vertical Turbulent Buoyant Jets - A Review of Experimental Data, 4, HMT, The Science and Applications of Heat and Mass Transfer (D. B. Spalding Ed.), Pergamon Press, 1980, pp. 28-35.

17. Birch, A. D., Brown, D. R., Dodson, M. G. and Swaffield, F., The Structure and Concentration Decay of High Pressure Jets of Natural Gas, Combust. Sci. and Tech., 36, 1984, pp. 249-261.

18. Winters, W. S. and Evans, G. H., Final Report for the ASC Gas-Powder Two-Phase Flow Modeling Project AD2006-09, Sandia National Laboratories Report No. SAND2006-7579.

19. Shapiro, A. H., The Dynamics and Thermodynamics of Compressible Fluid Flow - Vol. 1, 1953, The Ronald Press Co., New York, pp. 116-118.

20. Barlow, R. S. and Carter, C. D., Raman/Rayleigh/LIF Measurements of Nitric Oxide Formation in Turbulent Hydrogen Jet Flames, Combustion and Flame, 97, 1994, pp. 261-280.

21. www.ca.sandia.gov/TNF/2ndWorkshop/TNF2.html, 1997.

22. Leckner, B., Spectral and Total Emissivity of Water Vapor and Carbon Dioxide, Combustion and Flame, 19, 1972, pp. 33-48.

23. LaChance, J., Risk-Informed Separation Distances for Hydrogen Refueling Stations, Annual Hydrogen Conference and Hydrogen Expo USA, March 19 - 22, San Antonio, TX, 2007. 